МРНТИ 06.73.21

УДК 65.262 https://doi.org/10.51579/1563-2415.2021-3.08

\title{
ОСОБЕННОСТИ СОВРЕМЕННОГО КАЗАХСТАНСКОГО РЫНКА ПРОИЗВОДНЫХ ФИНАНСОВЫХ ИНСТРУМЕНТОВ
}

\author{
К.Ж. Бертаева, Д.О. Оналтаев \\ Алматинский гуманитарно-экономический университет, Алматы, Казахстан \\ e-mail: kul.bert@mail.ru
}

Аннотация: В научной статье предлагается аналитический обзор современного состояния казахстанского рынка производных финансовых инструментов, как одного из относительно нового сегмента отечественного финансового рынка. Определены ключевые условия, при которых формируются основные направления и положения фондового рынка и рынка производных финансовых инструментов. Рассмотрены системообразующие факторы, определяющие механизм функционирования фондовой и валютной биржс Казахстана. Дана оченка внешних факторов и условий совершения форвардных, своп операџий, опџионных сделок на казахстанской фондовой и валютной биржах и выявлены причины, замедляющие дальнейшее развитие казахстанского рынка производных финансовых инструментов. $B$ заключении предлагаются превентивные меры и направления в совершенствовании деятельности казахстанской фондовой биржи, рынка производных финансовых инструментов Казахстана и их особенности.

Ключевые слова: рынок производных финансовых инструментов, Национальный банк Казахстана, денежно-кредитное регулирование, финансово-банковская система РК, фондовая биржс, фондовый рынок, свопь, опчионы.

Основные положения. Особенности современного казахстанского рынка производных инструментов рассмотрены и изучены с учетом законодательных и нормативных положений, регулирующих и контролирующих финансовые и валютные операции, связанные с финансовыми деривативами и финансовыми производными инструментами. Все анализируемые положения, отражающие современное состояние казахстанского рынка финансовых деривативов, обоснованы мировым опытом и практикой применения этих финансовых инструментов и продуктов в казахстанских банках второго уровня. Все это дало в последствии дать возможность сделать правильные выводы о необходимости расширения и совершенствования казахстанского рынкаа производных фтнансовых инструментов.

Введение. Рынок производных финансовых инструментов в Республике Казахстан в настоящее время еще находится на стадии становления и медленного развития, характеризуемой применением финансовых инструментов, таких как форварды, свопы, опционы доллар/тенге и т.д. при низкой ликвидности и отсутствии активных участников рынка.

Как стало понятно, в процессе своей деятельности Национальный банк РК участвует в операциях с производными финансовыми инструментами для торговой деятельности. При этом известно, что производные финансовые инструменты основыва- 
ются на фундаментальных финансовых отношениях (кредите, займе, акции и т.п.), дополняют и развивают их. Функционирование производных финансовых инструментов как правило, в своей основе органично взаимосвязано с операциями по традиционным продуктам-инструментам. Производным финансовым инструментам присуще то положение, что при наступлении срока их исполнения в равной мере допустимо осуществить действительную реализацию ценностей, находящихся в основе договора, либо привести погашение обязательств-прав, ориентированное на существующие рыночные цены. Логичность современных решений выражается и в том, что участникам операций не требуется выступать в двойной роли: или как деятель на реальном (кассовом, наличном) рынке, или как деятель на срочном рынке.[98, с. 41]

Надо вспомнить, что в конце 2010 года Казахстанская фондовая биржа впервые запустила торги финансовыми деривативами - фьючерсом на курс доллара США к тенге и на индекс акций самой фондовой биржи. В условиях дефицита классических финансовых продуктов - акций и облигаций - производные финансовые инструменты были призваны поддержать текущие потребности инвесторов во вложениях. Производный финансовый инструмент включает некий базовый актив - ценную бумагу, товар, валюту - и в зависимости от движения цены базового актива инвестор может строить инвестиционные и спекулятивные стратегии, извлекая дополнительный доход.

Методы. При обосновании и решении методологических вопросов исследуемой проблемы автор опирался на фундаментальные положения современной экономической теории. Исследование основывалось на системном анализе, решение конкретных проблем достигалось с помощью сравнительного, статистического и графического анализа, с применением ранжирования, методов группировок.

Результаты и обсуждение. Практика показала, что казахстанские инвесторы не смогли правильно воспользоваться новым выгодным предложением. В 2016 году объем сделок по фьючерсам на курс доллара США к тенге составил всего 20 млн. долларов. По фьючерсам на индекс KASE в 2017 году сделок не было вовсе. [1] В последующие годы (2018-2020г.г.) объемы сделок увеличились только до 268 млн.долларов

Для современного состояния казахстанского рынка производных финансовых инструментов присуще их отсутствие в требованиях к региональным и местным органам управления, а в таких статьях, как требования к небанковским финансовым организациям, требования к государственным нефинансовым организациям, требования к негосударственным нефинансовым организациям финансовые деривативы имеют совсем малый удельный вес порядка 0,06-0,07\%.

Производные финансовые инструменты, включающие соглашения о будущей процентной ставке, валютные и процентные свопы, валютные и процентные опционы, а также другие их разновидности, первоначально учитываются в консолидированном бухгалтерском балансе по стоимости приобретения, а затем учитываются по справедливой стоимости, которая рассчитывается на основе котируемых рыночных цен, моделей дисконтирования потоков денежных средств и ценовых моделей. В случае использования методов дисконтирования денежных потоков предполагаемые будущие денежные потоки рассчитываются на основе наиболее вероятного и благоприятного прогноза руководства Национального Банка РК, в качестве ставки дисконтирования используется рыночная ставка по состоянию на отчетную дату по финансовому инструменту с аналогичными условиями. В случае использования ценовых моделей исходные данные определяются на основании рыночных показателей по состоянию на отчетную дату. Справедливая стоимость производных некотируемых финансовых инструментов, не входящих в листинг, определяется как сумма, которую Национальный Банк РК получил 
бы при расторжении договора по состоянию на отчетную дату с учетом текущих рыночных условий и кредитоспособности контрагентов по сделке. Производные финансовые инструменты учитываются в составе активов в случае положительной переоценки справедливой стоимости и в составе обязательств в случае отрицательной переоценки справедливой стоимости. [2].

Финансовые инструменты, оцениваемые по справедливой стоимости и изменения которой отражаются в составе прибыли или убытка за определенный период, представляют собой финансовые активы и обязательства, которые:

- покупаются или возникают с целью продажи или выкупа в ближайшем будущем;

- являются производными (за исключением производных финансовых инструментов, используемых как инструменты хеджирования);

- являются в момент первоначального признания по определению Национальным Банком РК в категорию оцениваемых по справедливой стоимости, изменения которой отражаются в составе прибыли или убытка за период.

Национальный Банк РК устанавливает финансовые активы и обязательства в категорию оцениваемых по справедливой стоимости, изменения которой отражаются в составе прибыли или убытка за период, при этом если выполняется одно из нижеуказанных условий:

- управление активами или обязательствами и их оценка осуществляются на основе справедливой стоимости;

- вышеприведенный подход полностью или существенно устраняет эффект несоответствия в бухгалтерском учете, который иначе существовал бы;

- актив или обязательство содержит встроенный финансовый инструмент, существенно изменяющий потоки денежных средств, которые при его отсутствии требовались бы по составленному договору.

Bсе производные финансовые инструменты, предназначенные для торговли, имеющие положительную справедливую стоимость отражены в консолидированной финансовой отчетности как активы. Все производные финансовые инструменты, предназначенные для торговли, имеющие отрицательную справедливую стоимость отражены в консолидированной финансовой отчетности как обязательство [99, с.14].

Финансовые активы и обязательства, оцениваемые по справедливой стоимости, изменения которой отражаются в составе прибыли или убытка за период, не классифицируются после первоначального признания.

Как правило, кредиты и дебиторская задолженность представляют собой непроизводные финансовые активы с фиксированными или определенными платежами, не котируемые на активно функционирующем рынке, за исключением тех, которые:

- Национальный Банк РК планирует продать незамедлительно или в самом ближайшем будущем;

- в момент первоначального признания Национальный Банк РК определяет в категорию оцениваемых по справедливой стоимости, изменения которой отражаются в составе прибыли или убытка за определенный период;

- в момент первоначального признания Национальный Банк РК определяет в категорию имеющихся в наличии для дальнейшей продажи;

- по некотируемым финансовым активам Национальный Банк РК может не возместить все первоначально осуществленные инвестиции по причинам, отличным обесценивания кредита. 
Финансовые активы, имеющиеся в наличии для продажи, представляют собой такие финансовые активы, которые определяются в категорию имеющихся в наличии для продажи или не попадают под определение кредитов и дебиторской задолженности инвестиций, которые удерживаются до срока погашения, или финансовых инструментов, которые оцениваются по справедливой стоимости, изменения которой отражаются в составе прибыли или убытка за определенный период.

Производные финансовые инструменты в позиции Национального банка РК на конец 2018 и начало 2019 г. составляют 1,6 \%, что характеризует и еще раз доказывает неразвитость казахстанского рынка финансовых деривативов [3, с. 30]. Такая же ситуация характерна и для 2020 г.

Объемы финансовых деривативов в 2018 году по требованиям к нерезидентам уменьшаются по сравнению с 2017 годом и составляют незначительный процент. Так в 2017 году этот показатель равен 1,3\%, а в 2018 году - 0,4\%. Такая ситуация объясняется, на наш взгляд, неразвитостью фондового рынка в Казахстане, несовершенством законодательной базы по введению производных финансовых инструментов, финансовых деривативов, плохой информированностью финансовых служб и клиентов казахстанских финансовых институтов о возможности использования и торговли финансовыми деривативами, невозможностью полноценно покупать и продавать данные финансовые инструменты на казахстанской фондовой бирже и другими факторами.

В 2019 году объемы финансовых деривативов составляли 1669 млн. тенге, а в 2020г. объемы финансовых деривативов увеличились незначительно до 2234 млн. тенге, что объясняется резким сокращением количества участников фондовой биржи.

Для современного состояния казахстанского рынка финансовых деривативов характерно их отсутствие в требованиях к региональным и местным органам управления, а в таких статьях, как требования к небанковским финансовым организациям, требования к государственным нефинансовым организациям, требования к негосударственным нефинансовым организациям финансовые деривативы имеют совсем малый удельный вес порядка $0,06-0,07 \%$.

Что касается обзора недепозитных финансовых организаций, то надо отметить незначительный удельный вес финансовых деривативов по всем статьям НБ РК - 96 и 735 млн. тенге в 2018 году, 1669 и 2065 млн. тенге в 2019 году, это отражено в таблице $1[4$, c. 26$]$.

На основе анализа были выявлены основные проблемы развития рынка производных финансовых инструментов, характерные последним годам, к ним относятся:

a) препятствия законодательного, юридического характера;

б) отсутствие регламентации должного внимания к данной проблеме со стороны регуляторов;

в) проблемы налоговые (в частности на невозможность сальдировать доходы и расходы при проведении деривативных операций, например по опционам, и искажение налогооблагаемой базы, сопряженное с проведением многих сделок);

г) проблемы отражения операций в бухгалтерском учете.

Без решения этих основных ключевых проблем с помощью государства дальнейшее развитие профессионального и ликвидного рынка производных финансовых инструментов невозможно. Существующие препятствия в виде отсутствия торговых площадок, технологий, правил, стандартов и терминологии носят значительно менее критический характер, чем вышеназванные проблемы, и, в общем-то, возможно преодолимы в ближайшие годы, так как их устранение зависит только от самого профессионального сообщества. 


\section{Таблица 1}

Финансовые деривативы в статьях недепозитных финансовых организачий Республики Казахстан

В миллионах тенге

\begin{tabular}{|l|l|l|l|}
\hline \multicolumn{1}{|c|}{ Показатели } & \multicolumn{1}{c|}{2017 г. } & \multicolumn{1}{c|}{2018 г. } & \multicolumn{1}{c|}{2019 Г. } \\
\hline Чистые внешние активы & -130157 & -201489 & -233677 \\
\hline Чистые внешние активы, СКВ & -125028 & -198725 & -226894 \\
\hline Требования к нерезидентам, СКВ & 23414 & 39821 & 52687 \\
\hline Переводимые депозиты & 1163 & 3665 & 5214 \\
\hline Другие депозиты & 17281 & 22414 & 32168 \\
\hline Ценные бумаги, кроме акций & 2457 & 4012 & 6012 \\
\hline Финансовые деривативы & 96 & 1669 & 3548 \\
\hline Акции и другие формы участия в капитале & 2405 & 4211 & 6879 \\
\hline Прочие счета к поручению & 13 & 108 & 325 \\
\hline $\begin{array}{l}\text { Минус: обязательства перед нерезидентами, } \\
\text { СКВ }\end{array}$ & 148442 & 198454 & 201487 \\
\hline Кредиты & 146349 & 235145 & 398712 \\
\hline Финансовые деривативы & 735 & 2065 & 4253 \\
\hline Прочие счета к оплате & 1357 & 1882 & 2879 \\
\hline Прочие чистые внешние активы & -5129 & -7812 & -8971 \\
\hline Валовые активы & 1585 & 2010 & 4425 \\
\hline Минус: Обязательства & 6714 & 7718 & 9852 \\
\hline Примечание - составлена на основе данных $H Б$ РК & & \\
\hline
\end{tabular}

Главная проблема слабых результатов деятельности рынка производных финансовых инструментов это - регуляторные препоны, которые были созданы. Существующая нормативная база по срочному рынку более приемлема для активно работающего спот- и срочного рынков, нежели для рынка производных инструментов в начальной стадии развития, когда для повышения к нему интереса надо было «смягчить» условиями входа и деятельности.

На отсутствие ликвидности указывает и ряд технических моментов. В первую очередь не работает институт маркетмейкеров. Как известно, основная задача маркетмейкера - поддерживать ликвидность рынка за счет выставления двусторонних котировок на покупку и продажу, у него должна быть возможность для хеджирования собственных рисков и перекрытия открытых позиций. В противном случае брокеру будет тяжело управлять этим финансовым инструментом. Он должен стать либо крупным банком с огромным объемом ликвидности, чтобы скупать с рынка все продаваемые ему объемы, либо выставлять цены, которые не будут интересны рынку. На сегодняшний день брокеры, желающие стать маркетмейкерами по фьючерсам, вынуждены самостоятельно искать варианты хеджирования собственных рисков, а поскольку вариантов практически нет, то и желающих тоже практически нет.

На текущий момент на фондовом рынке отсутствует возможность осуществления “коротких продаж”, что порождает высокие риски для потенциальных маркетмейкеров ввиду невозможности использования спот-рынка для хеджирования позиций по котировкам спроса на рынке производных финансовых инструментов. [5, с.96] 
Другой важной причиной, почему отсутствуют обороты по фьючерсу на индекс KASE, является слабая ликвидность по базовому активу - акциям, входящим в список данного индекса. На сегодняшний день индекс включает в себя лишь 7 акций (именно столько бумаг являются на данный момент по-настоящему ликвидными и могут входить в индекс). Это - акции двух крупных банков (БЦК, Народного банка Казахстана), трех сырьевых компаний, а также национального оператора связи Казахтелекома. Для сравнения, российский индекс ММВБ состоит из 30 наиболее ликвидных акций крупнейших российских эмитентов, а индекс Варшавской фондовой биржи включает в себя 20 крупнейших по капитализации компаний Польши из различных секторов экономики. [6].

Слабая количественная и отраслевая диверсификация индекса KASE делают вполне прогнозируемыми движения индекса и полностью зависимыми от ситуации на банковском и сырьевом рынках. К тому же слабая репрезентативность индекса приводит к тому, что индекс можно изменить одной крупной сделкой, как утверждают участники рынка финансовых деривативов. Отсутствие нормального базового рынка ведет к перекосам на бумажном рынке, проще говоря, к деятельности казино. Если в день по акциям проходят только две-три договорные сделки, невозможно получить нормальную расчетную цену фьючерса.

Что касается новых срочных инструментов (деривативов) казахстанского рынка конверсионных операций, которые могут быть востребованы рынком в ближайшие годы, к приоритетным финансовым инструментам можно отнести:

a) валютные форварды (FX outrights), торгуемые на внутреннем рынке;

б) валютные опционы - FX (Curency) Options;

в) расчетные форварды (NDS) для юридических лиц - клиентов; (spread);

г) валютный дилинг между форвардными датами - Forward/Forward swaps

д) кросс - валютные свопы (Cross currency swaps).

Финансовые инструменты срочного денежного рынка (процентные деривативы), являясь более сложными по своей природе и способам обращения, даже на мировых рынках относятся к разряду сложных инструментов финансового инжиниринга, позволяя банкам и корпорациям страховать проценты риска. Казахстану интересен опыт с данными инструментами на глобальных рынках, так, например, по данным Банка международных расчетов, средний дневной оборот процентными деривативами в 2019 г. составлял в мире свыше 5 трлн. дол. США.

Таблииа 2

Средний дневной оборот рынка прочентных деривативов в мире (2019 год)

\begin{tabular}{|l|l|l|}
\hline \multicolumn{1}{|c|}{ Инструмент } & \multicolumn{1}{|c|}{$\begin{array}{c}\text { Дневной оборот, } \\
\text { млрд. дол. }\end{array}$} & \multicolumn{1}{c|}{$\begin{array}{c}\text { Доля } \\
\text { в процентах }\end{array}$} \\
\hline Внебиржевые инструменты, & 4697 & 56,9 \\
\hline Из них: & & 4,1 \\
\hline Сделки FRA & 339 & 6,9 \\
\hline Процентные свопы & 571 & 2,8 \\
\hline Процентные опционы & 233 & 43,0 \\
\hline $\begin{array}{l}\text { Биржевые инструменты } \\
\text { (процентные фьючерсы и опционы) }\end{array}$ & 3554 & 100 \\
\hline Всего & 8251 & \\
\hline Примечание - Составлено автором на основе данных НБ РК & \\
\hline
\end{tabular}


Подавляющее большинство сделок межбанковского кредитования заключается на условиях однодневных кредитов, среди которых наиболее распространенным является, конечно, кредит типа «овернайт». На казахстанском рынке финансовых деривативов совершаются сделки на месяц и даже 3 месяца, но практически отсутствуют сделки на срок свыше полугода. Это еще раз подчеркивает краткосрочный характер казахстанского денежного рынка, вызванный, с одной стороны, достаточно короткими пассивами банков, а с другой стороны, ощущаемыми кредитными рисками банков - заемщиков (таблица 3).

\section{Таблииа 3}

Сроки (maturity) срочных сделок (деривативов) с прочентными инструментами, заключаемых казахстанскими банками

\begin{tabular}{|l|l|}
\hline \multicolumn{1}{|c|}{ Сроки } & \multicolumn{1}{c|}{ Доля в процентах } \\
\hline Менее 7 дней & 13,1 \\
\hline 7 дней - месяц & 9,4 \\
\hline $1-3$ месяцев & 10,6 \\
\hline $3-6$ месяцев & 3,1 \\
\hline $6-12$ месяцев & 14,4 \\
\hline Более 12 месяцев & 49,4 \\
\hline Итого & 100 \\
\hline Примечание - Составлено автором на основе данных НБ РК. \\
\hline
\end{tabular}

Следует признать, что аналогичную ситуацию можно встретить и на глобальных денежных рынках (например, на Лондонском рынке), когда значительную долю оборота занимают краткосрочные сделки (на срок до 3 месяцев).

Сроки, то есть процентные периоды, которые фигурируют в этих инструментах, распределены по различным периодам весьма неравномерно. Большинство сделок (почти 64\%) заключается со сроками свыше полугода, что вполне естественно, когда говорят о страховании процентных рисков по инструментам, имеющим достаточно длинные сроки до погашения (такие, как синдицированные кредиты, выпуски долговых ценных бумаг и другие) [6, с. 30].

Цели, которыми руководствуются или могут потенциально руководствоваться в будущем казахстанские банки при принятии решений о заключении сделок с процентными деривативами представлены в таблице 4.

\section{Таблица 4}

Цели, которыми руководствуются казахстанские банки при принятии решений о заключении сделок с прочентными деривативами

\begin{tabular}{|l|l|}
\hline \multicolumn{1}{|c|}{ Цели } & \multicolumn{1}{|c|}{ Доля в процентах } \\
\hline $\begin{array}{l}\text { Хеджирование процентных рисков (закрытие позиций в } \\
\text { других инструментах) }\end{array}$ & 36,9 \\
\hline Получение прибыли (трейдинг или спекуляции) & 28,9 \\
\hline Регулирование ликвидности банка & 24,2 \\
\hline Другие (выполнение заявок клиентов) & 10,0 \\
\hline Итого & 100 \\
\hline Примечание - Составлено автором \\
\hline
\end{tabular}


Хеджирование процентного риска заняло первое место в списке целеполагания при заключении сделок, что абсолютно естественно.

Анализ вопроса о трансграничных сделках с процентными деривативами позволяет сделать следующие выводы: во-первых, только пятая часть казахстанских банков работает с нерезидентами, во - вторых, большая часть финансовых сделок заключается с ними в иностранной валюте (долларах США).

Что касается фьючерсов на курс доллара США к тенге, то основной причиной слабого оборота является достаточно развитый внебиржевой рынок производных финансовых инструментов только по паре доллар США к тенге. В дополнение можно отметить низкий спекулятивный интерес банковских организаций к национальной валюте ввиду стабильности ее курса.

Такая ситуация происходит, несмотря на то, что срочный рынок, как минимум, предоставляет инструменты хеджирования валютных рисков экспортерам и импортерам и снижает спекулятивные риски спекулянтам базового актива. А как максимум, на различных спекулятивных стратегиях и арбитраже фьючерсами можно заработать. Однако казахстанские экспортеры и импортеры либо не пользуются возможностями срочного рынка, либо страхуют свои риски на более ликвидных площадках, хотя это экономически и оправданно, но не способствует развитию финансового рынка. Слаборазвитая спекулятивная составляющая - итог того, что институциональных инвесторов за нее не поощряют, а остальные инвесторы на рынке финансовых деривативов не имеют преимущественное положение.

Со своей стороны брокерские компании, как торговые посредники, считают, что производные инструменты на валюту не будут работать до тех пор, пока не будет существовать конкурентный валютный рынок. Идея фьючерса на валюту должна работать при условии наличия базового рынка: должны быть рыночные условия куплипродажи валюты и доступ к рынку должны иметь все желающие играть на фондовой бирже. Как известно, держателями иностранной валюты в РК являются экспортеры. Согласно законодательству они продают валютную выручку Национальному банку РК, но при этом обслуживающий их банк дает им свой внутренний курс, а на бирже продает валюту дороже. Как следствие, импортеры покупают у банка валюту по завышенной стоимости.

Несмотря на имеющиеся проблемы, участники финансового рынка позитивно оценивают перспективы дальнейшего развития рынка финансовых производных, в первую очередь за счет инициатив, которые продвигает сам рынок деривативов. В частности, брокеры неоднократно обращались к регулятору для получения официального разрешения проведения «коротких продаж» и намерены и дальше лоббировать решение этого вопроса в свою пользу.

Кроме того, в последующем Казахстанская фондовая биржа планирует запустить ряд новых инструментов: фьючерсы на отдельные акции индекса KASE, а также на дополнительные валютные пары, такие как евро/казахстанский тенге, евро/американский доллар и российский рубль/казахстанский тенге, но только при наличии маркетмейкеров. Для стимулирования интереса со стороны участников рынка биржа запланировала маркетинговые мероприятия по развитию отечественного рынка акций и деривативов, а именно работы по привлечению маркетмейкеров на условиях узких спредов, проведение обучающих семинаров и стимулирующих конкурсов для участников торгов и их клиентов, рекламные компании. [7].

Исходя из вышеизложенного, надо полагать, что развитию рынка производных финансовых инструментов в Казахстане, прежде всего, мешает отсутствие экономиче- 
ской основы, т.е. отсутствие объективного экономического интереса у субъектов казахстанской экономики. Наиболее активными участниками срочного рынка в настоящий момент являются спекулянты, а ведь основой срочного рынка должны быть операции по хеджированию рисков.

В Казахстане совершенно не развиты финансовые институты, традиционно являющиеся опорой срочного рынка в других странах, - страховые компании, различного вида инвестиционные, хеджевые фонды и т.д. Культура страхования рисков у казахстанских фирм практически отсутствует. Однако не менее существенные причины недостаточного развития срочного рынка лежат в области несовершенства законодательства и регулирования.

Казахстанское налоговое законодательство до настоящего времени не имеет четкой концепции налогообложения производных финансовых инструментов. Действующие нормы законодательства устанавливают порядок налогообложения отдельных видов финансовых инструментов - фьючерсов, опционов и форвардных контрактов, но более сложные финансовые операции остаются не востребованными, так как специальные правила налогообложения для них не установлены. В их отсутствие казахстанские налоговые органы применяют общие правила налогового законодательства, не учитывающие специфику данных операций. [8]

Первичный рынок с одной стороны, является наиболее интересным, но слабо регулируемым и быстроразвивающимся сектором финансового рынка. Инструменты, используемые на первичном рынке, кроме участия в операциях, преумножающих капитал, призваны увеличивать скорость оборота финансовых вложений, страховать ответственность и риски участников. Этих целей очень трудно достичь при больших сроках банковских расчетов, жестком контроле со стороны государства над операциями участников, высоком налоговом бремени (когда налогом облагается каждая сделка), значительных трудностях (из-за длительности сроков) привлечения к ответственности участников рынка. Надо считать, что до кардинального изменения экономической и политической ситуации в Казахстане срочный рынок не имеет больших перспектив развития.

Нестабильность ситуации на мировых финансовых рынках оказала свое определенное влияние на развитие казахстанского фондового рынка и рынка производных финансовых инструментов. Инвесторами были переоценены основные факторы уязвимости Казахстана, в частности: уровень внешнего долга страны, сопоставимый по размеру с ВВП; высокая доля банков в структуре внешнего долга, а также доля обязательств перед нерезидентами в совокупных обязательствах банков; расширение дефицита баланса счета текущих операций; высокая потенциальная нагрузка на золотовалютные резервы Национального Банка РК в случае возникновения дисбаланса между спросом и предложением иностранной валюты на внутреннем валютном рынке в условиях сокращения притока капитала.

Но, несмотря на указанные выше проблемы, именно сейчас наступил оптимальный момент для выхода отечественных компаний и финансовых институтов на фондовый рынок, учитывая возникшие сложности с банковским кредитованием и благоприятный режим, создаваемый государством в рамках реализации антикризисной программы.

В настоящее время рынок производных финансовых инструментов является одним из наиболее динамично развивающихся сегментов финансового рынка в мире.

Мощный импульс развитию валютного и фондового международных рынков дали такие факторы, как переход к плавающим валютным курсам, ослабление государ- 


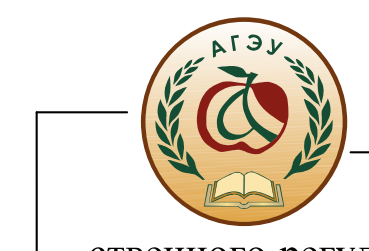

ственного регулирования в финансовой сфере, продолжающийся быстрый рост международной торговли товарами и услугами, достижение нового уровня в компьютерной и телекоммуникационной технологии и другие процессы. Инвестиционные операции стали действительно международными, а зарубежное инвестирование связано с повышенными рисками - риском изменения курса валюты, риском роста или падения процентных ставок по вкладам, риском колебания курсов акций и т.п., следовательно, возникла потребность в развитии рынка производных финансовых инструментов, который бы обеспечивал страхование этих рисков.

Многообразие форм и видов операций с производными финансовыми инструментами, постоянное совершенствование практики биржевой и внебиржевой торговли должны создать основу для эффективного функционирования рыночного механизма, сбалансирования рынка, снижения затрат на приобретение и реализацию продукции. Даже в условиях заметных колебаний рыночных цен операции с производными финансовыми инструментами позволяют фирмам и компаниям планировать свои издержки и прибыль на достаточно большие периоды, разрабатывать стратегию развития компаний с регулируемым риском, гибко сочетать различные формы инвестиций.

При нормальном уровне развития финансовой системы любой страны объем рынков производных инструментов значительно превышает объем рынков базовых активов. Но в Казахстане ситуация диаметрально противоположная - рынок производных финансовых инструментов до сих пор находится в начальном состоянии. Среди причин недостаточного развития данного рынка обычно называют как недостаточное разнообразие ликвидных финансовых инструментов и отсутствие достаточного количества кредитоспособных участников финансового рынка, так и наличие нерыночных ограничений, таких как жесткий валютный контроль и негибкая налоговая система.

Процентное соотношение заключенных сделок в валюте представлено в таблице 5.

Анализ данного вопроса о трансграничных сделках с процентными деривативами позволяет сделать следующие выводы: во-первых, только пятая часть казахстанских банков работает с нерезидентами, во - вторых, большая часть сделок заключается с ними в иностранной валюте (долларах США).

Таблица 5

Валюты, в которых заключаются срочные прочентные сделки

\begin{tabular}{|l|l|}
\hline Валюта & Доля в процентах \\
\hline KZT & 15,0 \\
\hline USD & 77,5 \\
\hline EUR & 7,5 \\
\hline Примечание - Составлено автором на основе данных НБ РК \\
\hline
\end{tabular}

Заключение. Анализ современного состояния рынка финансовых деривативов в Казахстане позволяет резюмировать главные выводы о текущем состоянии рынка финансовых деривативов, который является составной частью рынка производных финансовых инструментов:

1. На сегодняшний день срочный валютный рынок достаточно незрелый, доля срочных сделок по сравнению с кассовыми сделками существенно меньше, чем на развитых международных рынках, что свидетельствует о сравнительно низком использовании этого инструмента.

На фондовом рынке РК в структуре операций преобладает обычные форвардные 
сделки, FX outright (первое место) и сделки своп (второе место), что также отличается от мировой практики. По данным Банка международных расчетов за 2019 г. доля FX Swaps более чем в 4 раза превышает Forward Outrights.

2. Развитию рынка финансовых деривативов мешают сохраняющиеся проблемы законодательного характера (правовая неурегулированность срочных сделок), налоговые и бухгалтерские препятствия, проблемы информационного и квалификационного характера.

3. Тем не менее, рынок деривативов показывает определенный рост, увеличивается клиентский спрос внутри страны и за рубежом (в том числе по причине роста волатильности курса тенге к отдельным валютам).

Таким образом, исследованные и предложенные нами основные предпосылки и этапы формирования и развития казахстанского рынка финансовых деривативов, а также вышеприведенный анализ современного состояния казахстанского рынка финансовых деривативов дает нам основание констатировать необходимость его расширения и обновления за счет новых финансовых инструментов и новых финансовых операций.

\section{Список литературы:} 2000, c. 14

1. Бертаева К.Ж. Валютный рынок и валютные операции. Алматы, Экономика,

2. Официальный сайт НБ РК

3 Круглов А.В. Эволюция инструментов хеджирования. - СПб., 1996, 16 с.

4 Официальный сайт НБ РК

5 Захаров А.В., Станет ли фондовый рынок источником инвестиций // Эксперт. 2003. № 22, c.41 ты, 2009

6 Годовой отчет Национального банка Республики Казахстан за 2019 г. - Алма-

7 Шаматов Е.К. Портфель ценных бумаг. Алматы, «Сана-маркет», 2010, с. 96

8. Официальный сайт KASE

\section{Spisok literatury:}

s. 14

1. Bertaeva K.Zh. Valyutnyi rynok i valyutnye operatsii. Almaty, Ekonomika, 2000,

2. Ofitsialnyi sait NB RK

3 Kruglov A.V. Evolyutsiya instrumentov khedzhirovaniya. - SPb., 1996, 16 s.

4 Ofitsialnyi sait NB RK

5 Zakharov A.V., Stanet li fondovyi rynok istochnikom investitsii // Ekspert. 2003. № $22, \mathrm{~s} .41$

6 Godovoi otchet Natsionalnogo banka Respubliki Kazakhstan za 2019 g. - Almaty, 2009

7 Shamatov E.K. Portfel tsennykh bumag. Almaty, «Sana-market», 2010, s. 96

8. Ofitsialnyi sait KASE 


\title{
ТУЫНДЫ ҚАРЖЫ ҚҰРАЛДАРЫНЫН ҚАЗІРГІ ЗАМАНҒЫ ҚАЗАҚСТАНДЫҚ НАРЫҒЫНЫН ЕРЕКШЕЛІКТЕРІ
}

\author{
К.Ж. Бертаева, Д.О. Оналтаев \\ Алматы гуманитарль-экономикальқ университеті, Алматы, Қазақстан \\ e-mail: kul.bert@mail.ru
}

Аңдатпа: выллыми мақалада отандық құаржы нарывының салыстырммалы жаңуа сегментінің бірі ретінде туынды құаржы құралдарының қазақсттандық нарыгының қазіргі жай-күйіне талдамалы шолу ұсынылады. Қор нарывының және туынды қаржы құралдары нарывының негізгі бавыттары мен ережелері қалыптасатын негізгі шарттар айқындалды. Қазақстанның қор және валюта биржасының жұмыс істеу тетігін айқындайтын жүйе құраушы факторлар ққаралды. Қазақстан қор және валюта биржаларында форвардтық, своп операцияларын, опииондық мәмілелерін жасаудың сыртқы факторлары мен шарттарына бага берілді және туынды қаржы құралдарының қазақсттандық нарывының одан әрі дамуын бәсеңдететін себептер анықталды. Қорытындылда Қазақстан қ̧ор биржасының, Қазақстанның туынды құаржы құралдары нарывының қыззметін жетілдіруде алдын алу шаралары мен бавыттары және олардың ерекшеліктері ұсыныладыл.

Түйінді сөздер: туынды қаржы құралдары нарывы, Қазақсттан Ұлттық Банкі, ақчи-кредиттік реттеу, ҚР Қаржы-банк жүйесі, қ̧ор биржасы, қор нарывы, своптар, опџиондар.

\section{FEATURES OF THE MODERN KAZAKHSTAN MARKET OF DERIVATIVE FINANCIAL INSTRUMENTS}

\author{
K. Zh. Bertayeva, D.O. Onaltaev \\ Almaty Humanitarian and Economic University, Almaty, Kazakhstan \\ e-mail: kul.bert@mail.ru
}

\begin{abstract}
Summary. The scientific article offers an analytical review of the current state of the Kazakhstan market of derivative financial instruments, as one of the relatively new segments of the domestic financial market. The key conditions under which the main directions and positions of the stock market and the market of derivative financial instruments are formed are determined. The system-forming factors determining the mechanism of functioning of the stock and currency exchange of Kazakhstan are considered. The assessment of external factors and conditions for making forward, swap, and option transactions on the Kazakhstan stock and currency exchanges is given, and the reasons that slow down the further development of the Kazakhstan market of derivative financial instruments are identified. In conclusion, we propose preventive measures and directions for improving the activities of the Kazakhstan stock Exchange, the market of derivative financial instruments of Kazakhstan and their features.
\end{abstract}

Key words: market of derivative financial instruments, National Bank of Kazakhstan, monetary regulation, financial and banking system of the Republic of Kazakhstan, stock exchange, stock market, swaps, options. 